\title{
Time-varying dependence between stock and government bond returns: International evidence with dynamic copulas
}

\author{
Rania Jammazi ${ }^{\mathrm{a}, \mathrm{b}, \mathrm{c}, *}$, Aviral Kr. Tiwari ${ }^{\mathrm{d}}$, Román Ferrer ${ }^{\mathrm{e}}$, \\ Pablo Moya ${ }^{\mathrm{f}}$ \\ a IPAG Business School, Boulevard Saint Germain, Paris, France \\ ${ }^{b}$ Faculty of Management and Economic Sciences, Sousse, Tunisia \\ c LAREQUAD, Faculty of Management and Economic Sciences, Tunis, Tunisia \\ d Faculty of Management, Room No.: Block C-204, IBS Hyderabad, IFHE University, Dontanpalli (Village), \\ Shankerpalli Road, Hyderabad, A.P. 501203, India \\ e Department of Actuarial and Financial Economics, Faculty of Economics, University of Valencia, Avda. \\ Tarongers, s/n, 46022 Valencia, Spain \\ ${ }^{\mathrm{f}}$ Department of Economic and Financial Analysis, University of Castilla-La Mancha, C/Santa Teresa Jornet, \\ $s / n, 16071$ Cuenca, Spain
}

\section{A R T I C L E I N F O}

\section{Article history:}

Received 18 October 2014

Received in revised form 12 March 2015

Accepted 16 March 2015

Available online 27 March 2015

\section{JEL classification:}

C40

E44

F30

G15

Keywords:

Stock returns

Government bond returns

Dependence

Flight-to-quality

Time-varying copulas

\section{A B S T R A C T}

This paper investigates the dependence pattern between stock and long-term government bond returns for a wide range of developed countries over the last two decades by using a dynamic DCCGARCH-copula model. This approach allows obtaining a flexible and comprehensive description of the time variation in the linkage between stock and bond markets.

The empirical results show that the dependence structure between stock and 10-year government bond returns varies significantly over time for most countries. In particular, a positive stock-bond association is observed during the 1990s, while the relationship becomes negative from the early 2000s, supporting the presence of flight-to-quality effects. In addition, no evidence of asymmetric and tail dependence is found for the vast majority of countries.

() 2015 Elsevier Inc. All rights reserved.

\footnotetext{
* Corresponding author at: LAREQUAD, Faculty of Management and Economic Sciences, Tunis, Tunisia. Tel.: +216 20176 533/71233 318 .

E-mail addresses: jamrania2@yahoo.fr (R. Jammazi), aviral.eco@gmail.com, aktiwari@ibsindia.org (A.Kr. Tiwari), Roman.Ferrer@uv.es (R. Ferrer), Pablo.Moya@uclm.es (P. Moya).
} 


\section{Introduction}

Stocks and bonds constitute the two major asset classes traded on capital markets and the building blocks of most investment portfolios because of their different risk-return characteristics. Understanding the nature of the linkage between stock and government bond returns is of great interest for investors, portfolio managers and policy makers as it has crucial implications for asset allocation, portfolio diversification, risk management and monetary policy transmission. It has been frequently argued that the relationship between stock and bond returns is positive during periods of macroeconomic stability since both stock and bond markets are influenced by common macroeconomic factors such as inflation expectations or expected economic growth. However, there may also be a negative stock-bond association induced by the flight-to-quality phenomenon. Flight-to-quality refers to that, in times of stock market turbulence, investors become more risk averse and adjust their portfolios moving from risky assets such as stocks to safer assets such as long-term government bonds, thus causing a stock-bond decoupling.

The relationship between stock and government bond returns has received a great deal of attention in the financial literature since the seminal work of Keim and Stambaugh (1986). Linear correlation has been typically used as a measure of dependence between stock and bond returns due to its simplicity. Early contributions were based on rational expectations present value models that jointly price stocks and bonds under the assumption that the stock-bond correlation remains constant over time (Campbell \& Ammer, 1993; Shiller \& Beltratti, 1992). Subsequent empirical studies have, however, clearly illustrated the time-varying nature of the link between stock and government bond markets (Connolly, Sun, \& Stivers, 2005; Gulko, 2002; Ilmanen, 2003; Scruggs \& Glabadanidis, 2003). Multivariate GARCH (Generalized Autoregressive Conditional Heteroscedasticity) models have become the most popular approach to investigate the dynamic stock-bond correlation. The DCC (Dynamic Conditional Correlation)-GARCH model proposed by Engle (2002) has proven to be particularly well suited for describing the time-varying comovement between stock and bond markets (Aloui, Hammoudeh, \& ben Hamida, 2015; Andersson, Krylova, \& Vähämaa, 2008; Baur \& Lucey, 2009; Dacjman, 2012). An obvious limitation of multivariate GARCH processes is that they are built on the assumption that the conditional joint distribution of stock and bond returns follows an elliptical distribution with linear correlation, such as the multivariate Gaussian or Student- $t$. Nevertheless, this assumption is violated in many cases as the real association between financial returns is often more complicated, including for example nonlinear or tail dependence (Wu \& Lin, 2014).

In this context, a strand of research that models the dependence between stock and bond returns through copula functions has emerged with force over the last years (Lee, Huang, \& Lin, 2013; Yang \& Shigeyuki, 2015). This growing popularity has to do with the fact that copulas are able to reflect the whole dependence structure between financial asset returns, beyond linear correlation captured by multivariate GARCH processes. Moreover, copulas do not require imposing any assumption on the joint distribution of asset returns. Initial copula-based studies in this field concentrated on constant copulas (Durand, Junker, \& Szimayer, 2010; Gonzalo \& Olmo, 2005). However, more recent contributions consider time-varying (conditional) copulas, which allow better characterizing the dynamic comovement between stock and government bond markets (Chang \& Hsueh, 2013; Chui \& Yang, 2012; Nguyen \& Nguyen, 2014; Wu \& Liang, 2011; Wu \& Lin, 2014). These studies are predominantly focused on the US case (with the exception of Chang \& Hsueh, 2013) and document a significant variation over time in the stock-bond nexus. In particular, a negative association between stocks and bonds appears since the early 2000s, which has been attributed to the presence of flight-to-quality effects from stocks to long-term government bonds, mainly during periods of stock market uncertainty. Table A1 in Appendix A summarizes prior studies on the stock-bond link based on copula models.

The aim of this paper is to provide a thorough analysis of the dependence structure between stock and long-term government bond returns in a large sample of developed countries by adopting a time-varying DCC-GARCH-copula approach. This framework combines two approaches broadly used to characterize the dynamic comovement between variables, namely the DCC-GARCH model and conditional copulas. The DCC-GARCH-copula approach permits modeling the conditional correlation (via a DCC-GARCH) and the conditional dependence (via a copula) separately and simultaneously for 
non-normal multivariate distributions. Therefore, it is able to describe the time variation in the linkage between stock and bond markets in a more realistic way than standard DCC-GARCH or copula models.

This work contributes to the literature in several aspects. Firstly, to our knowledge, this is the first study that applies a DCC-GARCH-copula model to investigate the time-varying dependence pattern between stock and government bond returns. In this respect, a few recent studies have applied copula-based multivariate GARCH models in order to characterize the interdependence in financial markets taking into account the stylized facts (fat tails, volatility clustering, etc.) of financial returns usually reflected by multivariate GARCH models. For example, Lee and Long (2009) propose a copula multivariate GARCH model based on the combination of GARCH and copula models and demonstrate the superiority of this new approach on existing GARCH specifications. In a similar vein, using simulation methods Klein, Köck, and Tinkl (2010) prove the effectiveness of the strategy consisting of estimating the dependence of a BEKK-GARCH process via elliptical copulas. Subsequently, Thanh and Barassi (2014) show that a DCC-GARCH-copula approach is an efficient way to overcome the difficulties in modeling the financial dependence. Furthermore, they argue that the two-step procedure involving the combination of copulas and DCC-GARCH type models is the best solution for modeling the dependence in medium and large-sized portfolios. Following the spirit of these works, the DCCGARCH-copula approach proposed here can be seen as a flexible and effective filtering strategy to estimate the dependence structure between stock and sovereign bond markets. Secondly, the consideration of a wide range of countries, which includes the major European economies together with the more usual US case, helps to enhance the robustness of results. Thirdly, the use of a quite recent dataset enables us to ascertain whether some major economic events in recent years, such as the global financial crisis which started in late 2007 or the European sovereign debt crisis in 2010, have significantly altered the stock-bond connection.

Our results show that the linkage between stock and government bond returns has changed considerably over time. A positive relationship appears during the 1990s for virtually all countries, in line with the conventional wisdom that common macroeconomic conditions, such as the expected inflation or economic prospects, drive both stock and bond markets. In contrast, a negative stock-bond comovement is generally observed from the early 2000s, which may be attributed to the strengthened role of flight-to-quality episodes. This negative association is only broken for some peripheral euro area countries such as Greece, Spain, Portugal and Ireland, as well as Belgium, since the beginning of the European sovereign debt crisis in late 2009. This is because investors have fled stock and government bond markets of peripheral countries during the recent financial turmoil looking to invest in economies with more solid fundamentals. In addition, no evidence of asymmetric and tail dependence is found for most countries. This implies that the stock-bond comovement is not different in bearish and bullish markets and that the dependence is present most of the time, as opposed to primarily in extreme market conditions.

The rest of the article proceeds as follows. Section 2 introduces the new DCC-GARCH-copula framework used in this study. Section 3 describes the dataset employed. Section 4 presents and discusses the main empirical findings and Section 5 concludes. Appendices summarize the basic features of copula functions and DCC-GARCH models.

\section{Methodology}

After a short introduction to copulas, the model employed to characterize the time-varying dependence structure between stock and 10-year government bond returns is presented.

\subsection{Copula functions}

Copula functions represent a flexible instrument for modeling the dependence structure between variables. The concept of copula was first introduced by Sklar (1959), but it has only gained increasing popularity in economics and finance over the last decade. According to Sklar's theorem, any joint distribution function can be decomposed into its marginal distribution functions and a copula function that captures the complete dependence structure between the underlying variables (see more details in Appendix B). The attractiveness of copulas is primarily due to their great flexibility as the 
dependence between variables can be modeled separately from their marginal behavior. Furthermore, copulas allow capturing a wide variety of dependence structures, including nonlinear, asymmetric or tail dependence.

There are two main types of copula functions: static and time-varying copulas. Static, constant or unconditional copulas assume that the dependence between variables is time invariant. However, this assumption seems to be too restrictive since numerous empirical studies have shown that the linkages between economic and/or financial variables are time-varying. In this context, Patton (2006) extended the standard definition of copula to the conditional case. Time-varying, dynamic or conditional copulas introduced by Patton (2006) allow for time-variation in the dependence structure and are, therefore, able to characterize the relationship between variables in a more flexible way.

\subsection{Model specification}

In this study, a DCC-GARCH-copula model is proposed to describe the dependence structure between stock and 10-year government bond returns. The DCC-GARCH-copula approach offers a number of advantages on conventional DCC-GARCH and copula models. First, it is able to model separately and at the same time the conditional correlation by a DCC-GARCH model and the conditional dependence by a copula, capturing the stylized facts of financial data. Second, the DCC-copula approach is not subject to the restrictive requirements of DCC-GARCH models, such as the elliptical joint distribution and linear relationship between financial returns. Third, the DCC-copula model captures the nonlinear dependence ignored by conventional DCC-GARCH specifications.

The DCC-GARCH-copula approach is implemented in two steps. The first step consists in estimating a bivariate DCC-GARCH $(1,1)$ specification to capture the dynamic volatility and linear correlation structure between raw stock and bond returns (details on this model can be found in Appendix C). In the second step, the dependence parameters are estimated by using various time-varying copula functions taking as an input the standardized residuals from the previously estimated DCC-GARCH model. These standardized residuals are transformed by means of their empirical cumulative distribution functions to obtain series of data uniformly distributed on [0,1]. Four well-known copulas (Gaussian, Student- $t$, rotated Gumbel and Symmetrized Joe-Clayton or SJC) with different dependence structures and frequently applied in finance are applied in this study. Their functional forms and properties are discussed in Appendix B.

Given the abundant empirical evidence in the literature that the stock-bond linkage does not remain constant over time (Andersson et al., 2008; Baur \& Lucey, 2009; Connolly et al., 2005; Ilmanen, 2003) and that conditional copulas tend to have better performance than their unconditional counterparts, this paper focuses exclusively on time-varying copulas. In particular, the dynamic Gaussian, Student- $t$, rotated Gumbel and SJC copulas are estimated. The linear dependence parameters of these conditional copulas are assumed to evolve over time according to the model proposed by Patton (2006).

Various techniques have been utilized to estimate copula models, including the full maximum likelihood (FML) estimation, the canonical maximum likelihood (CML) approach, the method of Inference Functions for Margins (IFM) and the empirical copula. In this paper, the CML method (Cherubini, Luciano, \& Vecchiato, 2004) is adopted. Compared to traditional parametric approaches such as the FML and the IFM, no assumptions on the parametric form of marginal distributions are needed in the CML to estimate copula parameters. Using simulation techniques Kim, Silvapulle, and Silvapulle (2007) show that the CML performs better than FML and IFM methods when the marginal distributions are unknown, which is almost always the case in practice. The estimation by CML involves two steps. The first one consists of using the empirical cumulative distributions of the original variables $X_{t}$ and $Y_{t}$ to transform them into uniform variables $\hat{u}_{t}$ and $\hat{v}_{t}$. In the second step, copula parameters are estimated via maximum likelihood by solving the following problem:

$$
\hat{\theta}_{C M L}=\underset{\theta}{\arg \max } \sum_{t=1}^{T} \ln c\left(\hat{u}_{t}, \hat{v}_{t} ; \theta\right)
$$

where $\hat{\theta}_{C M L}$ are the copula parameters estimated by the CML method and $c(\cdot)$ stands for the density of the copula under consideration. Under weak regularity conditions, the CML estimator is consistent, 
asymptotically normal and fully efficient at independence (Genest, Ghoudi, \& Rivest, 1995). The performance of the different copula functions is evaluated by using the log likelihood function value and the Akaike information criterion (AIC) adjusted for small-sample bias (Reboredo \& Ugando, 2014; Reboredo \& Ugolini, 2015; Rodríguez, 2007).

\section{Data description}

Our dataset consists of national stock and bond market indices of 16 developed countries, which can be classified into four distinct groups: (1) Countries in the periphery of the euro area (Greece, Ireland, Portugal and Spain); (2) Countries belonging to the core of the euro area (Belgium, France, Germany and the Netherlands); (3) A number of non-eurozone members (Norway, Sweden, Switzerland and the UK); (4) A set of non-European countries which includes some of the major economies in the world (Australia, Canada, Japan and the US). The sample period extends from January 1993 to April 2013. The starting date of our analysis is January 1993 in order to avoid possible distortions in the linkage between stock and government bond returns caused by the turbulences in financial markets occurred in the context of the European exchange rate mechanism crisis during the second half of $1992 .{ }^{1}$

The stock market indices utilized are: DAX 30 (Germany), CAC 40 (France), IBEX 35 (Spain), FTSE 100 (the UK), ASX 300 (Australia), DJIA (the US), BEL 20 (Belgium), TSX (Canada), ATHEX (Greece), ISEQ (Ireland), NIKKEI 225 (Japan), AEX (the Netherlands), OSEBX (Norway), PSI 20 (Portugal), OMX 30 (Sweden) and SMI (Switzerland). The bond market indices employed are 10-year benchmark government bond price indices of each of the countries considered. Government bonds are used since they represent the risk of the country itself and are, therefore, appropriate for analyzing the presence of flight-to-quality effects between stock and bond markets. The use of the 10-year maturity has become increasingly popular in the literature on the stock-bond nexus (Andersson et al., 2008; Baele, Bekaert, \& Inghelbrecht, 2010; Brière, Chapelle, \& Szafarz, 2012; Kim, Moshirian, \& Wu, 2006) for several reasons. First, 10-year interest rates incorporate market expectations about future prospects for the economy and largely determine the cost of borrowing. Thus, long-term rates are likely to have a critical influence on investment decisions and profitability of firms and, hence, on their stock market performance. Second, long-term government bonds are often viewed as closer maturity substitutes to stocks, which may presumably increase the level of connection between both assets. Third, monetary policy operations are more likely to have a confounding influence on shorter-term securities, which also justifies the use of long-term interest rates at the expense of short-term rates. All return series have been collected from Thomson Financial Datastream. Following several other studies (EvrimMandaci, Kahyaoglu, \& Cagli, 2011; Wu \& Liang, 2011; Wu \& Lin, 2014), weekly return series (from Wednesday to Wednesday) are used (a total of 1058 observations). The weekly frequency is preferred to daily and monthly frequencies for various reasons. Firstly, daily data are more contaminated by noise and anomalies such as day-of-the-week effects or non-synchronous trading bias than weekly data. Secondly, compared to monthly data the weekly frequency provides a number of observations large enough to yield more reliable results. Stock and government bond returns have been calculated as the first log difference of two consecutive price indices.

Table 1 presents descriptive statistics of stock and government bond returns. The mean weekly stock and bond returns are close to zero in the great majority of cases and small relative to their standard deviations, which implies relatively high volatility in both markets. As expected, standard deviations reveal that 10 -year bond returns have significantly lower volatility that stock returns for virtually all countries, in line with the perceived safe haven status of government bonds. The only exception is the Greek 10-year sovereign bond, whose extreme variability can be explained in the context of the Greek debt crisis during recent years. The skewness value is negative for nearly all stock and bond returns, indicating that return series are left skewed. Kurtosis exceeds the reference value of the Gaussian distribution (equal to 3 ) for all cases. The non-normality of return series is corroborated by the Jarque-Bera test statistics. The results of the Ljung-Box Q-statistics for serial correlation of order 2 in raw returns show that the autocorrelation is not too severe and mainly affects stock returns

${ }^{1}$ It is worth noting that data on Greek 10-year government bond yields are available only from January 1999. 
Table 1

Descriptive statistics of weekly stock and 10-year government bond returns.

\begin{tabular}{|c|c|c|c|c|c|c|c|c|}
\hline & Mean & Std. Dev. & Skew. & Kurtosis & $\mathrm{JB}$ & $Q(2)$ & $Q^{2}(2)$ & $\mathrm{ARCH}(2)$ \\
\hline \multicolumn{9}{|c|}{ Panel A. Stock returns } \\
\hline United States & 0.0014 & 0.0225 & -0.64 & 7.31 & $890.51^{* * *}$ & 2.39 & $49.43^{* * *}$ & $42.52^{* * *}$ \\
\hline Australia & 0.0011 & 0.0204 & -0.51 & 6.38 & $547.88^{* * *}$ & 3.24 & $303.02^{* * *}$ & $216.92^{* * *}$ \\
\hline Japan & -0.0002 & 0.0304 & -0.37 & 6.45 & $550.85^{* * *}$ & 1.11 & $30.63^{* * *}$ & $27.69^{* * *}$ \\
\hline Canada & 0.0017 & 0.0279 & -0.86 & 7.58 & $1054.57^{* * *}$ & 0.90 & $119.63^{* * *}$ & $162.28^{* * *}$ \\
\hline Germany & 0.0015 & 0.0321 & -0.72 & 6.79 & $724.62^{* * * *}$ & $13.65^{* * *}$ & $68.98^{* * *}$ & $63.65^{* * *}$ \\
\hline France & 0.0006 & 0.0305 & -0.36 & 6.17 & $464.51^{* * *}$ & $22.66^{* * *}$ & $106.55^{* * *}$ & $99.10^{* * *}$ \\
\hline UK & 0.0007 & 0.0238 & -0.35 & 6.42 & $536.83^{* * *}$ & $11.25^{* * *}$ & $120.35^{* * *}$ & $108.24^{* * *}$ \\
\hline Spain & 0.0011 & 0.0316 & -0.40 & 4.55 & $135.19^{* * * *}$ & $12.48^{* * *}$ & $111.43^{* * *}$ & $100.06^{* * *}$ \\
\hline Norway & 0.0021 & 0.0306 & -0.87 & 8.92 & $1676.53^{* * *}$ & 1.54 & $275.99^{* * *}$ & $243.16^{* * * *}$ \\
\hline Switzerland & 0.0012 & 0.0259 & -0.43 & 7.16 & $796.06^{* * *}$ & $10.96^{* * *}$ & $176.14^{* * *}$ & $168.61^{* * *}$ \\
\hline Ireland & 0.0010 & 0.0301 & -0.72 & 7.87 & $1136.95^{* * *}$ & 3.20 & $119.63^{* * *}$ & $100.16^{* * *}$ \\
\hline Belgium & 0.0008 & 0.0276 & -0.47 & 8.01 & $1146.82^{* * *}$ & $5.23^{*}$ & $180.92^{* * *}$ & $158.27^{* * *}$ \\
\hline Sweden & 0.0017 & 0.0324 & -0.47 & 5.51 & $316.95^{* * *}$ & $22.75^{* * *}$ & $64.79^{* * *}$ & $63.60^{* * *}$ \\
\hline Netherlands & 0.0009 & 0.0313 & -0.56 & 8.47 & $1375.56^{* * *}$ & $22.48^{* * *}$ & $155.40^{* * *}$ & $135.80^{* * *}$ \\
\hline Portugal & 0.0006 & 0.0278 & -0.62 & 6.76 & $690.15^{* * *}$ & 2.37 & $59.76^{* * *}$ & $52.92^{* * *}$ \\
\hline Greece & 0.0003 & 0.0410 & -0.16 & 4.67 & $127.01^{* * *}$ & 2.16 & $63.84^{* * *}$ & $55.95^{* * *}$ \\
\hline \multicolumn{9}{|c|}{ Panel B. 10-year government bond returns } \\
\hline United States & 0.0003 & 0.0103 & -0.11 & 3.99 & $45.23^{* * *}$ & 3.78 & $29.23^{* * *}$ & $26.32^{* * *}$ \\
\hline Australia & 0.0004 & 0.0105 & -0.42 & 5.00 & $207.75^{* * *}$ & 1.42 & $19.68^{* * *}$ & $17.82^{* * *}$ \\
\hline Japan & 0.0004 & 0.0065 & -0.90 & 8.21 & $1338.90^{* * *}$ & $8.36^{* *}$ & $24.73^{* * *}$ & $22.45^{* * *}$ \\
\hline Canada & 0.0005 & 0.0087 & -0.26 & 3.88 & $45.88^{* * *}$ & 2.61 & $43.86^{* * *}$ & $39.94^{* * *}$ \\
\hline Germany & 0.0005 & 0.0079 & -0.38 & 3.89 & $60.02^{* * *}$ & 1.19 & $26.41^{* * *}$ & $23.55^{* * * *}$ \\
\hline France & 0.0005 & 0.0082 & -0.52 & 4.65 & $168.71^{* * *}$ & 3.15 & $34.06^{* * *}$ & $30.20^{* * *}$ \\
\hline UK & 0.0005 & 0.0091 & -0.09 & 4.44 & $92.55^{* * *}$ & $6.59^{* * *}$ & $77.32^{* * *}$ & $66.73^{* * *}$ \\
\hline Spain & 0.0007 & 0.0110 & 0.72 & 10.25 & $2409.07^{* * *}$ & 3.62 & $29.77^{* * *}$ & $26.34^{* * *}$ \\
\hline Norway & 0.0005 & 0.0094 & -0.45 & 6.93 & $717.55^{* * *}$ & 2.83 & $81.54^{* * *}$ & $67.33^{* * *}$ \\
\hline Switzerland & 0.0004 & 0.0069 & -0.26 & 4.51 & $112.20^{* * *}$ & 2.32 & $18.79^{* * *}$ & $17.68^{* * *}$ \\
\hline Ireland & 0.0004 & 0.0133 & -0.15 & 19.27 & $11,684.73^{* * *}$ & $7.89^{* *}$ & $339.64^{* * *}$ & $292.96^{* * *}$ \\
\hline Belgium & 0.0005 & 0.0084 & -0.26 & 6.26 & $478.85^{* * * *}$ & 2.89 & $153.92^{* * *}$ & $119.23^{* * *}$ \\
\hline Sweden & 0.0006 & 0.0099 & -0.68 & 7.31 & $900.32^{* * *}$ & 1.42 & $28.93^{* * *}$ & $25.93^{* * *}$ \\
\hline Netherlands & 0.0005 & 0.0077 & -0.54 & 3.96 & $92.31^{* * *}$ & 1.09 & $17.76^{* * *}$ & $16.39^{* * *}$ \\
\hline Portugal & 0.0004 & 0.0167 & -0.09 & 20.59 & $13,256.57^{* * *}$ & $9.11^{* *}$ & $129.82^{* * *}$ & $102.28^{* * *}$ \\
\hline Greece & -0.0011 & 0.0338 & -1.53 & 31.08 & $24,363.33^{* * *}$ & $14.39^{* * *}$ & $51.50^{* * *}$ & $45.82^{* * *}$ \\
\hline
\end{tabular}

Notes: This table displays descriptive statistics for weekly stock and 10-year government bond returns of the different countries considered during the period from January 1993 to April 2013. They include mean and standard deviation (Std. Dev.) values, as well as Skewness (Skew.) and Kurtosis measures. JB is the statistic of the Jarque-Bera test for normality. Q(2) and Q2(2) represent the Ljung-Box statistics for serial correlation of order 2 in returns and squared returns. Finally, ARCH(2) is the Lagrange multiplier test for autoregressive conditional heteroscedasticity of order 2 .

* Statistical significance at the $10 \%$ level.

** Statistical significance at the $5 \%$ level.

*** Statistical significance at the $1 \%$ level.

of some European countries. However, the Ljung-Box $Q^{2}$-statistics indicate that all squared returns exhibit significant serial correlation, suggesting possible volatility clustering. Finally, the ARCH LM test statistics confirm the presence of significant ARCH effects in all return series, thus supporting the use of a GARCH-type model. These summary statistics are consistent with the stylized facts on stock and bond returns typically found in the previous literature (Brière et al., 2012; Gómez-Puig, Sosvilla-Rivero, \& Ramos-Herrera, 2014; Lee et al., 2013; Scruggs \& Glabadanidis, 2003).

\section{Empirical results}

\subsection{Estimation of DCC-GARCH models}

Table 2 reports the estimation results of the bivariate DCC-GARCH $(1,1)$ model used to characterize the dynamic volatility and correlation structure between raw stock and government bond returns for 
Table 2

Parameter estimates of the DCC-GARCH(1,1) model between stock and 10-year government bond returns.

\begin{tabular}{|c|c|c|c|c|c|c|c|c|}
\hline Countries & US & Australia & Japan & Canada & Germany & France & UK & Spain \\
\hline \multicolumn{9}{|c|}{ Conditional mean equation } \\
\hline$\mu_{s}$ & $0.0025^{* * z}$ & $0.0018^{* * *}$ & $-0.0003^{* * *}$ & 0.0022 & $0.0030^{* * *}$ & $0.0013^{* * *}$ & $0.0013^{* * *}$ & $0.0013^{* * *}$ \\
\hline$\mu_{b}$ & $0.0002^{* * *}$ & $0.0002^{* * *}$ & $0.0007^{* * *}$ & $0.0004^{*}$ & $0.0004^{* *}$ & $0.0005^{* * *}$ & $0.0003^{* * *}$ & $0.0007^{* * *}$ \\
\hline \multicolumn{9}{|c|}{ Conditional variance equation } \\
\hline$\omega_{\mathrm{s}}$ & $0.012^{* * *}$ & 0.012 & $0.027^{* * *}$ & 0.020 & $0.026^{* * *}$ & $0.026^{* * *}$ & $0.015^{* * *}$ & $0.026^{* * *}$ \\
\hline$\omega_{\mathrm{b}}$ & $0.005^{* * *}$ & $0.006^{* * *}$ & $0.004^{* * *}$ & 0.004 & $0.007^{* * *}$ & $0.007^{* * *}$ & $0.004^{* * *}$ & $0.007^{* * *}$ \\
\hline$\alpha_{\mathrm{sb}}$ & $0.078^{* * *}$ & $0.071^{* * *}$ & $0.066^{* * *}$ & 0.036 & $0.050^{* * *}$ & $0.054^{* * *}$ & $0.075^{* * *}$ & $0.048^{* * *}$ \\
\hline$\alpha_{\mathrm{bs}}$ & $0.055^{* * *}$ & $0.001^{* * *}$ & $0.061^{* * *}$ & 0.023 & $0.001^{*}$ & $0.048^{* * *}$ & $0.097^{* * *}$ & $0.109^{* * *}$ \\
\hline$\beta_{\mathrm{sb}}$ & $0.846^{* * *}$ & $0.888^{* * *}$ & $0.912^{* * *}$ & $0.924^{* * *}$ & $0.951^{* * *}$ & $0.894^{* * *}$ & $0.736^{* * *}$ & $0.921^{* * *}$ \\
\hline$\beta_{\mathrm{bs}}$ & $0.860^{* * *}$ & $0.976^{* * *}$ & $0.945^{* * *}$ & $0.931^{* * *}$ & $0.983^{* * *}$ & $0.860^{* * *}$ & $0.883^{* * *}$ & $0.805^{* * *}$ \\
\hline \multicolumn{9}{|c|}{ Residual diagnostics } \\
\hline$Q(12)_{\mathrm{s}}$ & 3.382 & 4.358 & 2.585 & 8.594 & 3.422 & 3.150 & 7.611 & 6.202 \\
\hline$Q^{2}(12)_{s}$ & 7.446 & 15.286 & 1.831 & 10.662 & 1.223 & 2.625 & 3.480 & 8.476 \\
\hline$Q(12)_{b}$ & 11.511 & 7.378 & 6.475 & 6.327 & 6.001 & 5.292 & 1.168 & 9.283 \\
\hline$Q^{2}(12)_{b}$ & 7.626 & 4.984 & 5.676 & 6.941 & 11.552 & 4.453 & 0.300 & 1.745 \\
\hline Countries & Norway & Switzerland & Ireland & Belgium & Sweden & Netherlands & Portugal & Greece \\
\hline \multicolumn{9}{|c|}{ Conditional mean equation } \\
\hline$\mu_{s}$ & $0.0033^{* * *}$ & $0.0016^{* * *}$ & $0.0034^{* * *}$ & $0.0022^{* * *}$ & $0.0027^{* * *}$ & $0.0027^{* *}$ & $0.0023^{* * *}$ & 0.0014 \\
\hline$\mu_{b}$ & $0.0004^{* *}$ & 0.0003 & $0.0006^{* * *}$ & $0.0004^{* *}$ & $0.0006^{* * *}$ & $0.0003^{* *}$ & $0.0006^{* * *}$ & 0.0001 \\
\hline \multicolumn{9}{|c|}{ Conditional variance equation } \\
\hline$\omega_{\mathrm{s}}$ & $0.022^{* * *}$ & $0.020^{* * *}$ & $0.010^{* * *}$ & $0.019^{* * *}$ & $0.022^{* * *}$ & $0.013^{* * *}$ & $0.010^{* * *}$ & $0.032^{* * *}$ \\
\hline$\omega_{\mathrm{b}}$ & $0.004^{* *}$ & 0.004 & $0.003^{* * *}$ & $0.004^{* * *}$ & $0.003^{* * *}$ & $0.004^{* * *}$ & $0.004^{* * *}$ & $0.006^{* * *}$ \\
\hline$\alpha_{\mathrm{sb}}$ & $0.067^{* *}$ & $0.019^{* * *}$ & $0.004^{* * *}$ & $0.072^{* * *}$ & $0.076^{* * *}$ & $0.036^{* * *}$ & $0.007^{* * *}$ & $0.067^{* * *}$ \\
\hline$\alpha_{\mathrm{bs}}$ & $0.021^{* *}$ & 0.021 & $0.003^{* *}$ & $0.022^{* * *}$ & $0.027^{* * *}$ & 0.0004 & $0.0005^{* * *}$ & $0.1207^{* * *}$ \\
\hline$\beta_{\mathrm{sb}}$ & $0.874^{* *}$ & $0.729^{* * *}$ & $0.848^{* * *}$ & $0.618^{* * *}$ & $0.937^{* * *}$ & $0.821^{* * *}$ & $0.961^{* * *}$ & $0.928^{* * *}$ \\
\hline$\beta_{\mathrm{bs}}$ & $0.844^{* *}$ & $0.914^{* * *}$ & $0.961^{* * *}$ & $0.915^{* * *}$ & $0.964^{* * *}$ & $0.943^{* * *}$ & $0.857^{* * *}$ & $0.751^{* * *}$ \\
\hline \multicolumn{9}{|c|}{ Residual diagnostics } \\
\hline$Q(12)_{\mathrm{s}}$ & 7.893 & 9.654 & 8.729 & 2.671 & 7.807 & 5.519 & 2.502 & 10.693 \\
\hline$Q^{2}(12)_{s}$ & 0.996 & 3.125 & 9.264 & 0.145 & 7.775 & 9.666 & 7.022 & 4.982 \\
\hline$Q(12)_{b}$ & 8.901 & 6.685 & 1.147 & 8.446 & 4.279 & 12.083 & 11.630 & 8.431 \\
\hline$Q^{2}(12)_{b}$ & 2.941 & 0.696 & $8.706^{*}$ & 3.050 & 10.613 & 11.381 & 4.753 & 3.751 \\
\hline
\end{tabular}

Notes: This table shows the estimated parameters of the bivariate DCC-GARCH(1,1) models for all sampled countries. The subscripts $\mathrm{s}$ and $\mathrm{b}$ indicate stock returns and government bond returns, respectively. In the conditional mean equations, $\mu_{\mathrm{s}}$ and $\mu_{\mathrm{b}}$ denote the constant terms of stock and bond return equations, respectively. In the conditional variance equations, $\omega_{\mathrm{s}}$ and $\omega_{\mathrm{b}}$ are the respective constant terms. In turn, $\alpha_{\mathrm{sb}}\left(\alpha_{\mathrm{bs}}\right)$ represents the short-term volatility spillover from bond returns (stock returns) on stock returns (bond returns). Moreover, $\beta_{\mathrm{sb}}\left(\beta_{\mathrm{bs}}\right)$ represents the long-term volatility spillover from bond returns (stock returns) on stock returns (bond returns). $\mathrm{Q}(12)$ and $\mathrm{Q}^{2}(12)$ denote the Ljung-Box test statistics of order 12 for serial correlation of standardized and squared standardized residuals, respectively.

${ }^{*}$ Statistical significance at the $10 \%$ levels.

** Statistical significance at the $5 \%$ levels.

*** Statistical significance at the $1 \%$ levels.

each of the 16 countries under investigation. Overall, the results of the DCC-GARCH model are quite homogeneous across countries. As shown in Table 2, most of the parameter estimates in the conditional mean and variance equations are statistically significant regardless of asset class and country. This is consistent with strong evidence of time-varying volatility in financial returns and justifies the choice of the DCC-GARCH $(1,1)$ specification. The conditional variance coefficients are positive and highly significant in almost all cases. The coefficients for the lagged conditional variance $\beta_{\mathrm{i}}$ are much larger relative to the coefficients for the past return innovations $\alpha_{\mathrm{i}}$, indicating an important persistence effect in the volatility of stock and bond returns. Moreover, the volatility for each asset return displays a highly persistent behavior and only a slow mean reversion since the sum of estimated coefficients $\alpha$ and $\beta$ in each variance equation is very close to unity in all cases. There is evidence of significant short-term persistence volatility spillovers from bond returns to stock returns $\left(\alpha_{\mathrm{sb}}\right)$ and also, to a 
Table 3

Goodness-of-fit (GoF) tests for the DCC-GARCH(1,1) models.

\begin{tabular}{lllllllll}
\hline Countries & US & Australia & Japan & Canada & Germany & France & UK & Spain \\
\hline K-S & 0.890 & 0.842 & 0.672 & 0.931 & 0.955 & 0.933 & 0.971 & 0.833 \\
CvM & 0.904 & 0.664 & 0.982 & 0.761 & 0.876 & 0.967 & 0.985 & 0.861 \\
A-D & 0.954 & 0.973 & 0.472 & 0.694 & 0.691 & 0.936 & 0.693 & 0.591 \\
First moment & 0.919 & 0.882 & 0.563 & 0.722 & 0.733 & 0.890 & 0.963 & 0.754 \\
Second moment & 0.933 & 0.712 & 0.883 & 0.917 & 0.883 & 0.884 & 0.852 & 0.927 \\
Third moment & 0.992 & 0.670 & 0.799 & 0.835 & 0.728 & 0.689 & 0.994 & 0.950 \\
Fourth moment & 0.772 & 0.974 & 0.940 & 0.985 & 0.913 & 0.777 & 0.855 & 0.606 \\
& & & & & & & & \\
Countries & Norway & Switzerland & Ireland & Belgium & Sweden & Netherlands & Portugal & Greece \\
\hline K-S & 0.890 & 0.842 & 0.672 & 0.931 & 0.955 & 0.933 & 0.971 & 0.833 \\
CvM & 0.904 & 0.664 & 0.982 & 0.761 & 0.876 & 0.967 & 0.985 & 0.861 \\
A-D & 0.954 & 0.973 & 0.472 & 0.694 & 0.691 & 0.936 & 0.693 & 0.591 \\
First moment & 0.919 & 0.882 & 0.563 & 0.722 & 0.733 & 0.890 & 0.963 & 0.754 \\
Second moment & 0.933 & 0.712 & 0.883 & 0.917 & 0.883 & 0.884 & 0.852 & 0.927 \\
Third moment & 0.992 & 0.670 & 0.799 & 0.835 & 0.728 & 0.689 & 0.994 & 0.950 \\
Fourth moment & 0.772 & 0.974 & 0.940 & 0.985 & 0.913 & 0.777 & 0.855 & 0.606 \\
\hline
\end{tabular}

Notes: This table presents the $p$-values of the Kolmogorov-Smirnov, Cramer-von Mises and Anderson-Darling goodness-of-fit tests. The $p$-values of the LM tests of serial independence of the first four moments of filtered stock and government bond returns from the DCC-GARCH(1,1) model are also reported. Values below 0.05 indicate rejection of the null hypothesis that the model is well specified. For more details on these misspecification tests see Patton (2006). K-S, CvM and A-D denote the Kolmogorov-Smirnov, Cramer-von Mises and Anderson-Darling tests, respectively. As usual, *, ${ }^{* *}$ and ${ }^{* * *}$ indicate statistical significance at the $10 \%, 5 \%$ and $1 \%$ levels, respectively.

lesser extent, from stock returns to bond returns $\left(\alpha_{\mathrm{bs}}\right)$ for most countries. There is also significant evidence of long-term persistence volatility spillovers from stock returns to bond returns $\left(\beta_{\mathrm{bs}}\right)$ and, to a lesser degree, from bond returns to stock returns $\left(\beta_{\mathrm{sb}}\right)$. In addition, the Ljung-Box statistics fail to reject the null of no serial correlation in the standardized residuals and their squares, suggesting that the DCC-GARCH $(1,1)$ model seems to be well specified for all countries. ${ }^{2}$

Table 3 presents the results of LM tests for serial dependence of the probability integral transforms of filtered returns and also the Kolmogorov-Smirnov, Cramer-von Mises and Anderson-Darling misspecification tests to check the empirical adequacy of estimated DCC-GARCH $(1,1)$ models. These tests have a key role as if the DCC-GARCH model is misspecified, then the copula model will also be invalid. They assess the null hypothesis that filtered stock and bond returns are i.i.d. uniform in the interval $(0,1)$ by comparing the empirical distribution and the specified theoretical distribution function. The $p$-values of all these tests indicate that the null hypothesis of the correct specification of the distribution function cannot be rejected for any of the return series at the conventional significance levels. Hence, it can be concluded that the DCC-GARCH $(1,1)$ models are not misspecified and, therefore, the DCC-GARCH-copula approach can correctly capture the dependence structure between stock and government bond returns.

Existing studies that apply copula-based multivariate GARCH models (Klein et al., 2010; Lee \& Long, 2009; Thanh \& Barassi, 2014) argue that a multivariate GARCH specification such as the DCC-GARCH is a perfectly valid filtering strategy as it captures the usual stylized facts of financial returns without losing any information content. In other words, the estimation of the interdependence between the underlying variables will not be affected by the use of a DCC-GARCH model when a conditional copula is applied on the resulting filtered returns to describe the dependence structure. In order to legitimate the feasibility of this filtering strategy within the framework of the stock-bond linkage, next we compare the estimates, reported in Table 4, of two common measures of dependence such as the linear correlation and Kendall's tau between the filtered stock and bond returns from univariate GARCH

\footnotetext{
${ }^{2}$ For the sake of brevity, the figure which displays the dynamic correlation between stock and government bond returns for all sampled countries resulting from the estimated DCC-GARCH$(1,1)$ model is not reported here, but it is available from the authors upon request.
} 


\section{Table 4}

Dependence between filtered stock and government bond returns.

\begin{tabular}{|c|c|c|c|c|c|c|c|c|}
\hline Countries & US & Australia & Japan & Canada & Germany & France & UK & Spain \\
\hline \multicolumn{9}{|c|}{ Dependence between the DCC-GARCH filtered stock and bond returns } \\
\hline Linear correlation & -0.126 & -0.052 & -0.285 & -0.107 & -0.204 & -0.114 & -0.083 & 0.094 \\
\hline Kendall's tau & -0.068 & -0.043 & -0.211 & -0.078 & -0.095 & -0.054 & -0.053 & 0.063 \\
\hline \multicolumn{9}{|c|}{ Dependence between the univariate GARCH filtered stock and bond returns } \\
\hline Linear correlation & -0.179 & -0.078 & -0.278 & -0.109 & -0.215 & -0.103 & -0.102 & 0.129 \\
\hline Kendall's tau & -0.097 & -0.049 & -0.210 & -0.084 & -0.097 & -0.048 & -0.054 & 0.074 \\
\hline Countries & Norway & Switzerland & Ireland & Belgium & Sweden & Netherlands & Portugal & Greece \\
\hline \multicolumn{9}{|c|}{ Dependence between the DCC-GARCH filtered stock and bond returns } \\
\hline Linear correlation & -0.097 & -0.152 & 0.053 & -0.045 & -0.085 & -0.119 & 0.091 & 0.158 \\
\hline Kendall's tau & -0.061 & -0.067 & 0.015 & 0.008 & -0.063 & -0.070 & 0.035 & 0.060 \\
\hline \multicolumn{9}{|c|}{ Dependence between the univariate GARCH filtered stock and bond returns } \\
\hline Linear correlation & -0.104 & -0.176 & 0.048 & -0.039 & -0.073 & -0.105 & 0.102 & 0.143 \\
\hline Kendall's tau & -0.071 & -0.074 & 0.018 & 0.002 & -0.058 & -0.090 & 0.056 & 0.054 \\
\hline
\end{tabular}

Notes: This table presents the estimated values of the linear correlation coefficient and Kendall's tau between stock and government bond returns filtered by using the DCC-GARCH( 1,1$)$ model and standard univariate GARCH(1,1) models.

models and those from the DCC-GARCH specification, respectively. ${ }^{3}$ The Kendall's tau is becoming a measure of association between variables extensively used in practice as it captures nonlinear dependence, unlike the traditional linear correlation. The relationship between the linear dependence $\rho_{t}$ and the nonlinear dependence Kendall's tau $\rho_{t}$ is given by ${ }^{4}$ :

$$
\tau_{t}=\frac{2 \arcsin \left(\rho_{t}\right)}{\pi}
$$

The Kendall's tau can also be represented in terms of copula functions as follows:

$$
\tau_{t}=4 \int_{[0,1]^{2}}^{\infty} C(u, v, \delta) d C(u, v, \delta)-1
$$

A deeper look at Table 4 reveals that the dependence measures obtained via DCC-GARCH filtered returns are very close to those calculated from univariate GARCH filtered returns for most countries. This result means that the DCC-GARCH filtering strategy hardly impacts the dependence between stock and government bond returns.

To further check the robustness of this finding, Fig. 1 displays the Gaussian copula scatterplots of filtered stock and government bond returns. As can be seen, the scatterplots clearly illustrate a similar dependence structure between filtered stock and bond returns regardless of the specification used (univariate GARCH or DCC-GARCH models) to filter the return series. Therefore, the similar dependence pattern between the two types of filtered returns validates the choice of the DCC-GARCH model as an appropriate filtering strategy.

\subsection{Estimation of conditional copula models}

The estimated parameters of the time-varying dependence between filtered stock and 10-year government bond returns in each country for the four conditional copula models considered are presented in Table 5. In terms of the values of the log likelihood function and the AIC adjusted for small-sample

\footnotetext{
${ }^{3}$ The optimal univariate GARCH models have been chosen on the basis of values of the log likelihood function and the Akaike information criterion for each pair of stock and government bond returns. The estimates of these models are not reported since we focus exclusively on the DCC-GARCH model. Furthermore, the filtered returns of univariate GARCH models are considered only for comparison purposes.

4 See Heinen and Valdesogo (2008) for more details.
} 


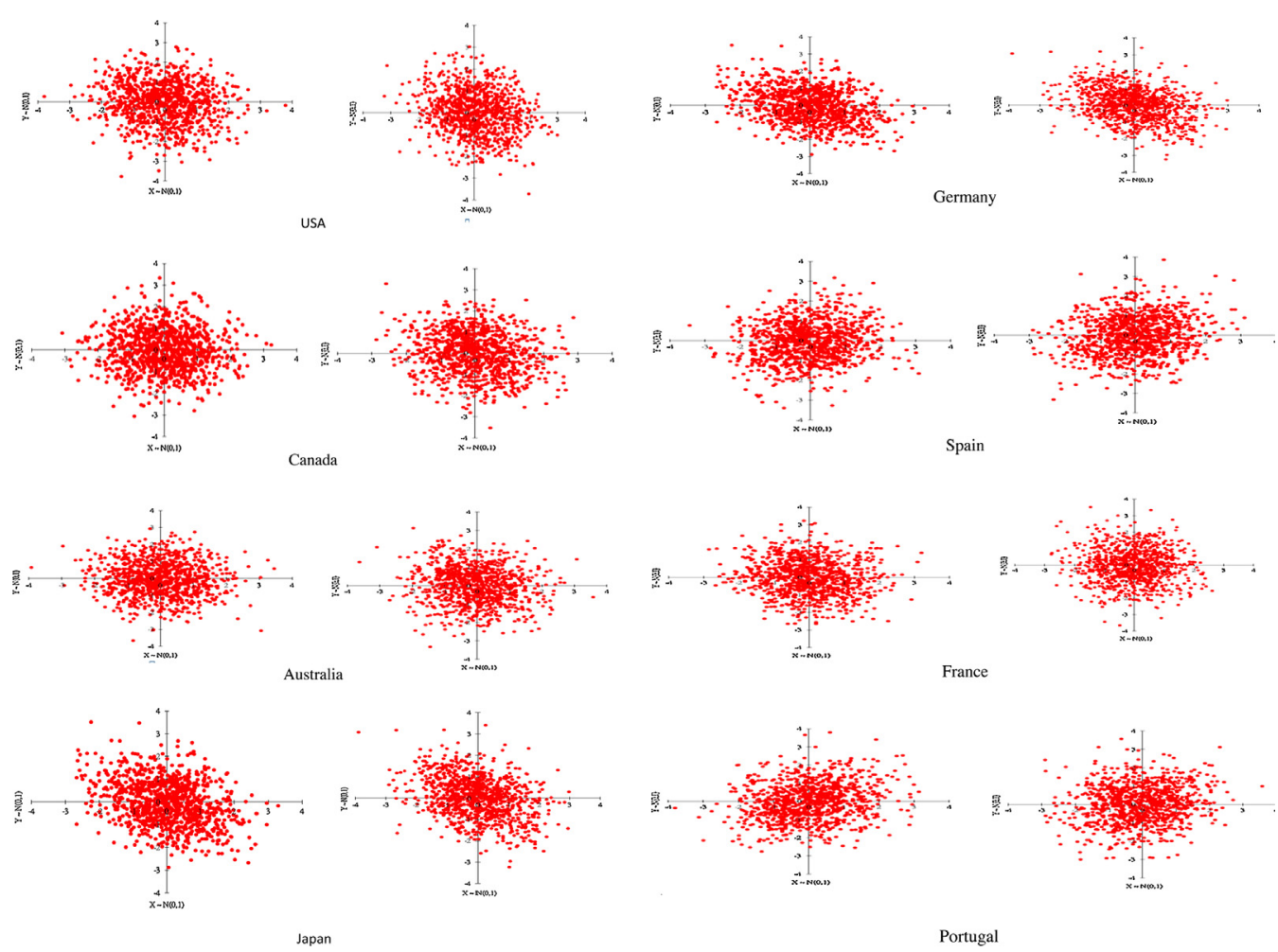

Fig. 1. Gaussian copula scatterplots of filtered returns of stocks and government bonds. Notes: The left-hand graphs display the scatterplots for filtered stock and government bond returns by using the DCC-GARCH $(1,1)$ model, while the right-hand graphs contain the scatterplots for filtered stock and government bond returns via univariate GARCH(1,1) models for the different countries.

bias, the time-varying Gaussian copula appears as the most suitable model for describing the dependence structure between stock and bond markets in the vast majority of countries, followed by the time-varying Student- $t$ copula. In contrast, the dynamic rotated Gumbel and SJC copulas have the worst performance. In this respect, it is worth mentioning that the dominance of the Gaussian copula has been also documented by the recent works of Chui and Yang (2012) and Nguyen and Nguyen (2014), which focus on the stock-bond dependence in different countries and sample periods by using copula-based models. The parameter $\Psi_{1}$ measures the level of persistence in the dependence and $\Psi_{2}$ captures the variation in the dependence process for the two elliptical copula functions (Gaussian and Student- $t$ ). Instead, for the conditional rotated Gumbel and SJC copulas these features are captured by parameters $\beta$ and $\alpha$, respectively.

The persistence parameter $\Psi_{1}$ is significant at the $1 \%$ level in time-varying Gaussian and Student- $t$ copulas for almost all countries. This parameter is always positive with the only exceptions of Ireland and Greece. This result implies a high degree of persistence over time in the dependence pattern between international stock and government bond returns, consistent with findings from earlier related studies (Chang \& Hsueh, 2013; Wu \& Liang, 2011; Wu \& Lin, 2014). The parameter $\Psi_{2}$ is also strongly significant for nearly all countries, indicating substantial variations over time in the stock-bond dependence. The positive values of this parameter for all countries suggest that the latest information on stock and bond returns is a meaningful indicator for modeling the dynamic stock-bond dependence. However, the fact that the variation parameter $\Psi_{2}$ is relatively small compared to the persistence parameter $\Psi_{1}$ for most countries demonstrates the predominance of persistence effects. The high number of significant parameter estimates in dynamic elliptical copulas implies that the 
Table 5

Parameter estimates of time-varying copulas.

\begin{tabular}{|c|c|c|c|c|c|c|c|c|}
\hline Countries & US & Australia & Japan & Canada & Germany & France & UK & Spain \\
\hline \multicolumn{9}{|c|}{ Time-varying Gaussian copula } \\
\hline$\Psi_{0}$ & -0.0090 & -0.0037 & -0.0059 & -0.0026 & -0.0030 & -0.0083 & 0.0036 & 0.0002 \\
\hline$\Psi_{2}$ & $0.1510^{* * *}$ & $0.0752^{* *}$ & $0.0536^{*}$ & $0.0607^{* * *}$ & $0.0689^{* * *}$ & $0.0537^{* * *}$ & $0.1301^{* * *}$ & $0.0864^{* * *}$ \\
\hline$\Psi_{1}$ & $1.9438^{* * *}$ & $2.0152^{* * *}$ & $2.0062^{* * *}$ & $2.0052^{* * *}$ & $2.0358^{* * *}$ & $2.0531^{* * *}$ & $1.9909^{* * *}$ & $2.0231^{* * *}$ \\
\hline LL & 72.6954 & 60.1763 & 55.1534 & 42.9255 & 79.5477 & 71.2870 & 81.3255 & 76.0289 \\
\hline AIC & -139.3682 & -114.3301 & -104.284 & -79.8284 & -153.073 & -136.551 & -156.63 & -146.035 \\
\hline RANK & $1 / 4$ & $1 / 4$ & $1 / 4$ & $1 / 4$ & $1 / 4$ & $1 / 4$ & $1 / 4$ & $1 / 4$ \\
\hline \multicolumn{9}{|c|}{ Time-varying Student- $t$ copula } \\
\hline$\Psi_{0}$ & -0.0048 & -0.1231 & -0.4611 & -0.0019 & -0.0054 & -0.0068 & 0.0025 & 0.0013 \\
\hline$\Psi_{2}$ & $0.0756^{* * *}$ & $0.05418^{* * *}$ & 0.1482 & $0.0361^{* *}$ & $0.0612^{* * *}$ & $0.0316^{* * *}$ & $0.0443^{* *}$ & $0.0501^{* * *}$ \\
\hline$\Psi_{1}$ & $1.9729^{* * *}$ & $2.0429^{* * *}$ & 0.2681 & $1.9987^{* * *}$ & $1.9583^{* * *}$ & $2.0568^{* * *}$ & $2.0273^{* * *}$ & $2.0290^{* * *}$ \\
\hline$N$ & $5.0000^{* * *}$ & $5.0000^{* * *}$ & $5.0000^{* * *}$ & $5.0000^{* * *}$ & $5.0000^{* * *}$ & $5.0000^{* * *}$ & $5.0000^{* * *}$ & $5.0000^{* * *}$ \\
\hline LL & 73.2806 & 45.0766 & 39.3660 & 32.3438 & 63.4331 & 71.4933 & 69.5630 & 71.7350 \\
\hline AIC & -138.5237 & -97.1277 & -70.6940 & -56.6500 & -98.7429 & -134.95 & -131.09 & -135.4319 \\
\hline RANK & $2 / 4$ & $2 / 4$ & $2 / 4$ & $2 / 4$ & $2 / 4$ & $2 / 4$ & $2 / 4$ & $2 / 4$ \\
\hline \multicolumn{9}{|c|}{ Time-varying rotated Gumbel copula } \\
\hline$\omega_{\mathrm{L}}$ & 0.1650 & $0.6274^{* *}$ & $0.8054^{*}$ & $0.4847^{* * *}$ & $0.4135^{* *}$ & $0.2605^{* * *}$ & -0.1122 & 0.4797 \\
\hline$\alpha_{\mathrm{L}}$ & $-0.6786^{* *}$ & $-1.0166^{* * *}$ & $-0.8057^{*}$ & $-0.9154^{* * *}$ & $-0.8322^{* * *}$ & $-0.7391^{* * *}$ & $-0.5202^{* * *}$ & $0.2860^{* * *}$ \\
\hline$\beta_{\mathrm{L}}$ & $1.0519^{* * *}$ & $0.7608^{* * *}$ & 0.0013 & $0.8927^{*}$ & $0.7480^{*}$ & $0.9160^{* * *}$ & $1.3734^{* * *}$ & $-1.5142^{* * *}$ \\
\hline LL & 11.4265 & 9.3659 & -0.0316 & 6.2961 & 12.9977 & 16.9534 & 18.0096 & 36.461 \\
\hline AIC & -16.8306 & -12.7092 & 6.0861 & -6.5698 & -19.9726 & -27.8841 & -29.996 & -66.899 \\
\hline RANK & $3 / 4$ & $3 / 4$ & $3 / 4$ & $3 / 4$ & $3 / 4$ & $3 / 4$ & $3 / 4$ & $3 / 4$ \\
\hline \multicolumn{9}{|c|}{ Time-varying SJC copula } \\
\hline$\omega_{\mathrm{U}}$ & -13.1698 & -13.1698 & -13.1698 & -13.1698 & -13.1698 & -13.1698 & -13.169 & -0.2837 \\
\hline$\beta_{\mathrm{U}}$ & 0 & 0 & 0 & 0 & 0 & 0 & 0 & -11.9866 \\
\hline$\alpha_{\mathrm{U}}$ & 0 & 0 & 0 & 0 & 0 & 0 & 0 & 0.7808 \\
\hline$\omega_{\mathrm{L}}$ & -13.1698 & -13.1698 & -13.1698 & -13.1698 & -13.1698 & -13.1698 & -13.169 & 0.9772 \\
\hline$\beta_{\mathrm{L}}$ & 0 & 0 & 0 & 0 & 0 & 0 & 0 & -12.6369 \\
\hline$\alpha_{\mathrm{L}}$ & 0 & 0 & 0 & 0 & 0 & 0 & 0 & 0.7843 \\
\hline LL & -9.1954 & -4.8777 & -26.3838 & -9.3193 & -14.4881 & -8.1057 & -6.5060 & 25.5622 \\
\hline AIC & 30.4698 & 21.8343 & 64.8475 & 30.7177 & 41.0562 & 28.2913 & 25.0920 & -39.0444 \\
\hline RANK & $4 / 4$ & $4 / 4$ & $4 / 4$ & $4 / 4$ & $4 / 4$ & $4 / 4$ & $4 / 4$ & $4 / 4$ \\
\hline Countries & Norway & Switzerland & Ireland & Belgium & Sweden & Netherlands & Portugal & Greece \\
\hline \multicolumn{9}{|c|}{ Time-varying Gaussian copula } \\
\hline$\Psi_{0}$ & 0.0003 & -0.0033 & 0.1575 & $0.0005^{* * *}$ & -0.0077 & -0.0881 & 0.0264 & $0.7424^{* * *}$ \\
\hline$\Psi_{2}$ & $0.0548^{* * *}$ & $0.0648^{* * *}$ & $0.5085^{* * *}$ & $0.0977^{* * *}$ & $0.0541^{* * *}$ & $0.9159^{* * *}$ & $0.3575^{* * *}$ & $2.7324^{* * *}$ \\
\hline$\Psi_{1}$ & $1.9972^{* * *}$ & $1.9829^{* * *}$ & $-1.9217^{* * *}$ & $1.9501^{* * *}$ & $2.0626^{* * *}$ & 0.6613 & 1.0753 & $-0.979^{* * *}$ \\
\hline LL & 31.2120 & 33.8346 & 7.0312 & 33.2866 & 77.1182 & 68.0810 & 19.0988 & 570.049 \\
\hline AIC & -56.4012 & -61.6463 & -8.0395 & -60.5504 & -148.214 & -130.139 & -32.1742 & $-1.1341 \mathrm{e}+03$ \\
\hline RANK & $1 / 4$ & $1 / 4$ & $3 / 4$ & $1 / 4$ & $1 / 4$ & $2 / 4$ & $2 / 4$ & $2 / 4$ \\
\hline \multicolumn{9}{|c|}{ Time-varying Student- $t$ copula } \\
\hline$\Psi_{0}$ & -0.0013 & -0.0005 & 0.0454 & $0.2547^{* * *}$ & -0.0089 & -0.0076 & -0.0002 & $0.6944^{* * *}$ \\
\hline$\Psi_{2}$ & $0.0287^{* *}$ & $0.0251^{* * *}$ & $0.2881^{* *}$ & $0.3442^{* * *}$ & $0.0335^{* * *}$ & $0.0999^{* * *}$ & $0.0280^{* *}$ & $0.0789^{* * *}$ \\
\hline$\Psi_{1}$ & $1.9910^{* * *}$ & $2.0098^{* * *}$ & -0.6514 & $1.7533^{* * *}$ & $2.0709^{* * * *}$ & $1.9620^{* * *}$ & $1.9942^{* * * *}$ & $2.0541^{* * *}$ \\
\hline$N$ & $5.0000^{* * *}$ & $5.0000^{* * *}$ & $5.0000^{* * *}$ & $5.0000^{* * * *}$ & $5.0000^{* * *}$ & $5.0000^{* * * *}$ & $5.0000^{* * *}$ & $5.0000^{* * *}$ \\
\hline LL & 9.4427 & 30.5585 & 9.6555 & 22.4522 & 74.4692 & 73.2781 & 21.4453 & 566.0455 \\
\hline AIC & -10.8474 & -53.0790 & -11.2730 & -37.4599 & -140.9005 & -138.518 & -34.8515 & $-1.0341 \mathrm{e}+03$ \\
\hline RANK & $2 / 4$ & $2 / 4$ & $2 / 4$ & $2 / 4$ & $2 / 4$ & $1 / 4$ & $1 / 4$ & $3 / 4$ \\
\hline \multicolumn{9}{|c|}{ Time-varying rotated Gumbel copula } \\
\hline$\omega_{\mathrm{L}}$ & $0.6935^{* * *}$ & $2.0209^{* * * * *}$ & $-1.2718^{* * *}$ & -0.1710 & 0.4029 & 0.4744 & 0.1611 & $0.9133^{* * * *}$ \\
\hline$\alpha_{\mathrm{L}}$ & $-1.0901^{* * *}$ & $-2.1931^{* * *}$ & 0.4257 & -0.3796 & $-0.8504^{* * *}$ & $-0.9006^{* * *}$ & 0.4575 & $0.2206^{* * *}$ \\
\hline$\beta_{\mathrm{L}}$ & $0.8914^{* * *}$ & $0.3542^{* * *}$ & $1.9114^{* * *}$ & $1.0538^{* * *}$ & $0.9390^{* * *}$ & $0.8870^{* * *}$ & -1.2902 & -1.6287 \\
\hline LL & 3.9930 & 0.4909 & 9.5550 & 9.7015 & 10.1971 & 7.7975 & 16.6582 & 478.0008 \\
\hline AIC & -1.9633 & 5.0410 & -13.087 & -13.380 & -14.3714 & -9.5723 & -27.2929 & -949.9781 \\
\hline RANK & $3 / 4$ & $3 / 4$ & $1 / 4$ & $2 / 4$ & $3 / 4$ & $3 / 4$ & $3 / 4$ & $4 / 4$ \\
\hline
\end{tabular}


Table 5 (Continued)

\begin{tabular}{lllllllll}
\hline Countries & Norway & Switzerland & Ireland & Belgium & Sweden & Netherlands & Portugal & Greece \\
\hline \multicolumn{2}{l}{ Time-varying SJC copula } & & & & & & & \\
$\omega_{\mathrm{U}}$ & -13.1698 & -13.1698 & -9.7043 & -13.1698 & -13.1698 & -13.1698 & -10.5813 & 1.8087 \\
$\beta_{\mathrm{U}}$ & 0 & 0 & -2.0290 & 0 & 0 & 0 & -1.7017 & -2.7869 \\
$\alpha_{\mathrm{U}}$ & 0 & 0 & -0.0027 & 0 & 0 & 0 & -0.0027 & -0.0447 \\
$\omega_{\mathrm{L}}$ & -13.1698 & -13.1698 & -11.016 & -13.1698 & -13.1698 & -13.1698 & 3.3145 & -3.2966 \\
$\beta_{\mathrm{L}}$ & 0 & 0 & -0.2141 & 0 & 0 & 0 & -21.5690 & -0.3946 \\
$\alpha_{\mathrm{L}}$ & 0 & 0 & -0.0002 & 0 & 0 & 0 & -5.4759 & 1.6092 \\
LL & -10.3479 & -11.7244 & 2.0336 & -0.4255 & -8.1938 & -10.5811 & 12.1382 & 814.3551 \\
AIC & 32.7758 & 35.5288 & 8.0129 & 12.9310 & 28.4677 & 33.2422 & -12.1941 & $-1.6166 \mathrm{e}+03$ \\
RANK & $4 / 4$ & $4 / 4$ & $4 / 4$ & $4 / 4$ & $4 / 4$ & $4 / 4$ & $4 / 4$ & $1 / 4$ \\
\hline
\end{tabular}

Notes: This table displays the estimated dependence parameters of the time-varying Gaussian, Student- $t$, rotated Gumbel and SJC (Symmetrized Joe Clayton) copulas between stock and 10-year government bond returns for a large sample of developed countries. LL and AIC represent values of the log likelihood function and Akaike information criterion adjusted for small-sample bias, respectively. RANK reflects the ranking of each conditional copula within the four estimated copulas in terms of LL and AIC.

* Statistical significance at the $10 \%$ levels.

** Statistical significance at the $5 \%$ levels.

**** Statistical significance at the $1 \%$ levels.

dependence is time-varying and thus a constant copula model may not be adequate to describe the dependence structure between stock and bond markets.

The dominance of the conditional Gaussian copula over the dynamic SJC and rotated Gumbel copulas suggests that the linkage between stock and bond returns for the vast majority of countries is not characterized by tail and/or asymmetric dependence. This means that the stock-bond dependence seems to occur most of the time, and not primarily during extreme market events, and that stock and bond markets do not tend to boom or to crash together for most countries. In addition, the absence of asymmetric dependence implies that the dependence structure between stock and bond returns is the same in upturn and downturn markets.

\subsection{Dependence time paths}

Given the supremacy of the conditional Gaussian copula over the remaining copula functions, the analysis presented here focuses exclusively on the results of the time-varying Gaussian copula. Fig. 2 illustrates the time path and average of the dependence structure between stock and government bond markets for all sampled countries. Notice that the average dependence (dashed red line) is generally weak (values near to zero) with very few exceptions. The highest mean dependence (in absolute value), with a value close to 0.7, is found for Greece, followed by Japan and Germany, in which the level of dependence is around -0.3 and -0.2 , respectively. As for the time-varying dependence, graphs in Fig. 2 show two common features for the vast majority of countries. First, there is a substantial time variation in the conditional dependence between stock and bond returns throughout the sample period, which supports the use of dynamic copulas rather than constant copulas. Second, most countries exhibit a rather similar pattern of dependence over time. In particular, a positive linkage is observed in the 1990s for all countries except Japan, while the stock-bond comovement becomes negative since the early 2000s. The existence of two basic regimes in the relationship between stock and government bond markets is consistent with previous research in this field (Andersson et al., 2008; Baur \& Lucey, 2009; Chiang, Li, \& Yang, 2014; Connolly et al., 2005).

A possible explanation for the positive stock-bond association suggested by Andersson et al. (2008) and Ilmanen (2003) is related to the expected inflation. In an environment of relatively high inflation expectations, such as most of the 1990s, stock and bond prices tend to move in the same direction. It is well known that rising expected inflation raises discount rates and adversely affects bond prices, but the impact of the increasing inflation on stock prices is ambiguous given that both expected cash flows and discount rates are likely to be affected. However, as noted by Ilmanen (2003), during periods of high inflation expectations the discount rate effect prevails over changes in cash flow expectations and, 

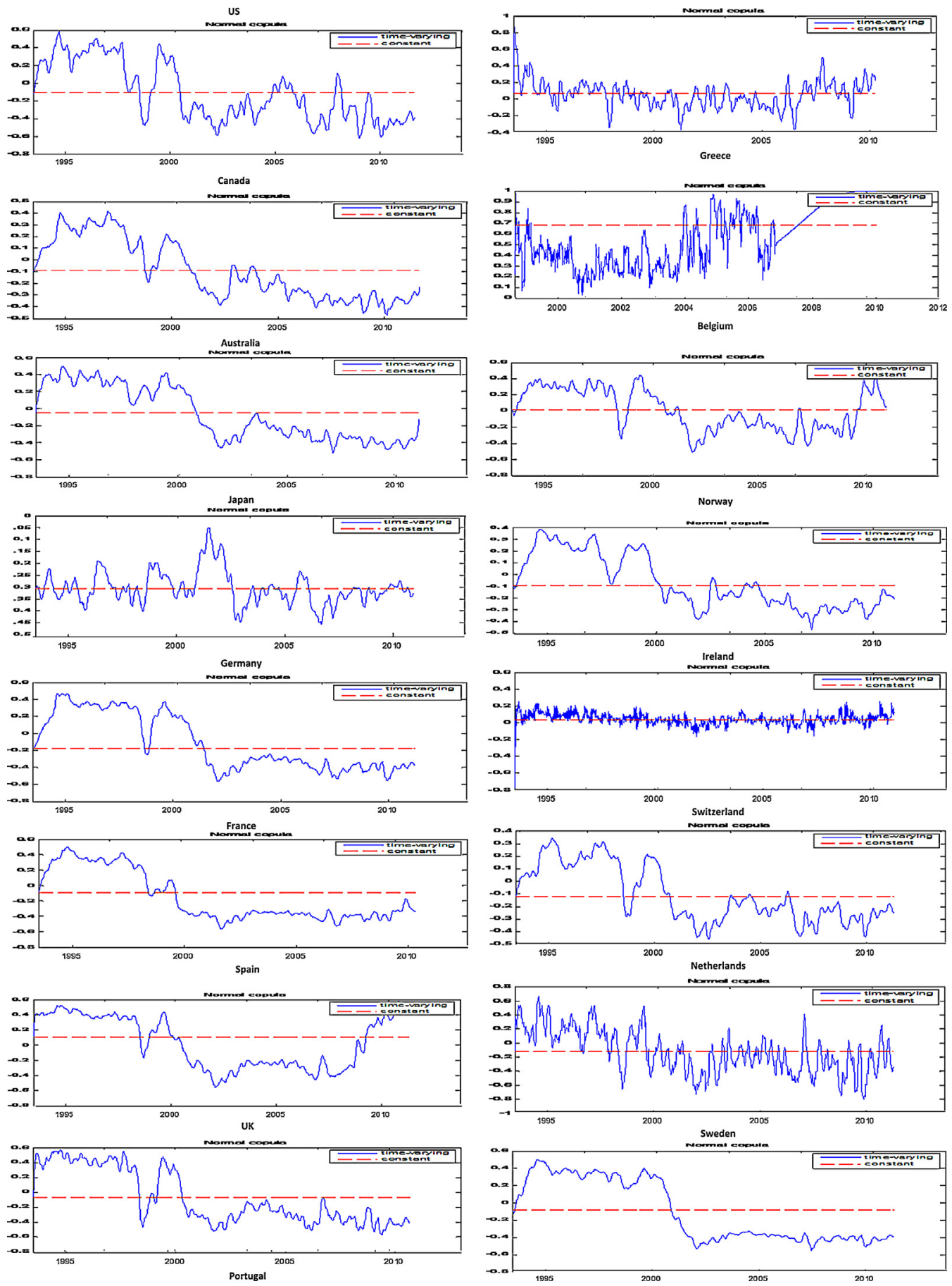

Fig. 2. Time path of the stock-bond dependence for the time-varying Gaussian copula. 
hence, high expected inflation also has a negative impact on stock prices, thereby inducing a positive stock-bond link. In a similar vein, $\operatorname{Li}$ (2002) argues that the comovement between stocks and bonds is stronger during periods of higher uncertainty about long-term expected inflation. In such a context, inflation is a primary concern for market participants, so that any rise in interest rates is perceived as a harbinger of increased inflation risk and hurts both government bond and stock markets, thus generating a positive association between them. Another argument to justify the positive relationship between stock and bond returns is based on the idea that when a country's economic prospects are good, as was the case during the 1990s, both stock and sovereign bond markets reflect the optimism of a growing economy and tend to go up in unison (see, e.g., Chiang et al., 2014).

In contrast, the negative stock-bond connection during the 2000s may be ascribed to the flightto-quality phenomenon, according to which in periods of stock market uncertainty investors become more risk averse and move funds out of assets perceived as risky such as stocks to invest in safer assets such as long-term government bonds. The numerous episodes of financial market turbulence in the 2000 s, including the bursting of the information technology bubble in 2000 , the 9/11 attacks, the Iraq war in 2003, the global financial crisis in 2008 and the subsequent European sovereign debt crisis in 2010, have made flight-to-quality behavior more common, leading to a decoupling between stock and sovereign bond markets.

As shown in graphs of Fig. 2, the greatest absolute values of the negative association between stock and government bond returns appear since late 2008 for most countries, which indicates that the degree of stock-bond dependence seems to have increased with the recent global financial crisis. It is also important to underscore the significant level of positive dependence during the first half of the 1990s for most countries, highlighting the beneficial effect of the marked decline in the expected inflation during the first half of the 1990s on the performance of stock and government bond markets.

The results by country reveal that the highest level of stock-bond dependence is found for Greece, with values close to 1 from the start of the Greek sovereign debt crisis at the end of 2009. This is not surprising taking into account the serious economic problems faced by this country, which led to the simultaneous collapse of Greek stock and government bond markets, thus generating a strong positive link between both markets. On the contrary, Ireland emerges as the country with the lowest degree of stock-bond association during the period of study. This lack of connection suggests that Irish stock and government bond markets have moved independently of each other. This idiosyncratic performance may be the result of the low liquidity, thin trading and relatively small capitalization of Irish capital markets. It is also particularly striking the case of Japan, which displays a negative stock-bond comovement during the full sample period. This peculiar behavior may have its origin in the deflationary environment in which the Japanese economy is mired since the early 1990s. In this context, rises in expected inflation and interest rates are interpreted as bullish for the Japanese equity market because they raise hopes of an exit from the deflationary spiral, which induces a negative nexus between stock and bond returns.

The dynamics of stock-bond comovement in the US is fully in line with that documented by various recent copula-based studies (Chui \& Yang, 2012; Durand et al., 2010; Nguyen \& Nguyen, 2014; Wu \& Lin, 2014). Specifically, a positive relationship between stock and government bond returns is found in the 1990s, a period of relatively high inflation and low uncertainty about real economic activity. Instead, in times of greater uncertainty such as the 2000s, US stock and bond markets have moved in the opposite direction owing primarily to the considerable decline in long-term Treasury yields caused by flight-to-quality phenomena. This finding confirms the status of US Treasuries as one of the preferred safe haven assets for global investors. The development of the stock-bond dependence in the other non-European countries (Australia and Canada) bears a close resemblance to that observed for the US, suggesting that Australian and Canadian government debt markets have been also beneficiary of flight-to-quality flows.

In addition, the results show a clear segmentation between European countries in terms of the link between stock and bond markets over the past few years. On the one hand, there is a group of countries made up of several eurozone core member states, namely Germany, France and the Netherlands, and a number of non-eurozone advanced countries, such as Norway, Sweden, Switzerland and the UK, which exhibit a pattern of stock-bond comovement very similar to that of the US. This means these countries have been regarded as safer economies because of their better economic prospects and healthier public 
finances. Therefore, they have benefited from flight-to-quality flows from other asset classes and other more vulnerable markets, so that their sovereign debt has enjoyed a large demand and long-term bond yields have reached historical lows. On the other hand, a positive relationship between stock and government bond returns emerges in recent years, especially from early 2010 , for a set of countries in the periphery of the euro area, namely Greece, Spain, Portugal and Ireland. This positive association arises because stock and sovereign bond markets of these countries have moved during recent years in a bearish direction due to the combination of deteriorating macroeconomic fundamentals, increasing concern about debt sustainability and decline in risk appetite in international financial markets. Thus, since the start of the European sovereign debt crisis in late 2009 investors have perceived stock and government bonds of peripheral countries as highly risky assets and have opted for the joint selling of these assets and the shift of their portfolios toward more solid economies such as the US, the UK, Canada or core euro area countries. This evidence coincides with that obtained by Dacjman (2012) and Perego and Vermeulen (2013) for the countries most affected by the debt crisis in the euro area. It is also worth noting that the pattern of linkage between Belgian stock and government bond returns over the last few years is very similar to that observed for peripheral economies. This close association with the periphery of the eurozone seems to reflect the growing concern of investors about Belgium's ability to reduce its excessive level of public debt and the risk of spreading the crisis to Belgium. In fact, the high Belgian debt-to-GDP ratio (between $80-100 \%$ in the period prior to the global financial crisis) together with the expensive state bailout of two of its largest banks (Fortis and Dexia) may have played a significant role in this context.

\section{Concluding remarks}

This paper investigates the dynamic comovement between stock and long-term government bond markets for a wide range of advanced countries over the past two decades by using a time-varying DCC-GARCH-copula approach. This novel framework allows modeling the conditional correlation (by a DCC-GARCH) and the conditional dependence (by a copula) separately and simultaneously, thus providing a more complete description of the time-varying dependence structure between financial markets.

Our results reveal significant variability over time in the dependence structure between stock and government bond returns for most countries. The sign and intensity of the dependence differ depending on the specific period considered, although the stock-bond association exhibits a rather similar pattern across the major developed economies. A positive comovement between stock and bond returns is found in the 1990s for virtually all countries. This finding may be attributed to the role played by the expected inflation and economic prospects as key drivers of stock and bond market performance during this period. However, the prevailing negative relationship between stock and government bond markets since the early 2000s is consistent with the flight-to-quality phenomenon, according to which the stock-bond linkage strongly decreases in periods of increased stock market turbulence. Interestingly, the recent eurozone sovereign debt crisis seems to have caused a clear shift in the pattern of dependence between stock and bond markets in several European peripheral countries such as Greece, Spain, Portugal and Ireland, as well as Belgium. In particular, a positive stock-bond link emerges since the beginning of the sovereign debt crisis in late 2009. This suggests that international investors have moved away from stock and government bond markets of these countries driven by the great pessimism about future economic prospects to invest in financial assets of economies with better fundamentals and improved economic outlook. Another interesting finding is the absence of asymmetric and tail dependence for the vast majority of countries. This implies, on the one hand, that the level of connection between stock and government bond markets is not different during market upturns and downturns. On the other hand, the lack of tail dependence suggests that stock and bond markets do not tend to boom or to crash together and the dependence is not especially strong during extreme market conditions, but it is present most of the time.

The evidence presented here may have important practical implications for market participants. For instance, investors and portfolio managers should take into account the time-varying nature of the stock-bond association in their portfolio allocation decisions and diversification and risk management strategies. For policy makers, the lack of tail dependence seems to demonstrate the success of 
unconventional monetary policy actions (being quantitative easing the most popular measure) adopted by the major central banks since 2008 in maintaining the stability of financial markets.

\section{Acknowledgements}

The authors wish to express their sincere gratitude to Marcelo Brutti Righi for his valuable comments and suggestions to improve this paper. The authors also wish to thank the comments of the editor of North American Journal of Economics and Finance, Prof. Hamid Beladi, as well as the two anonymous referees

\section{Appendix A.}

See Table A1.

\section{Appendix B. Presentation of the Copula approach}

In this appendix, we briefly present the concept and main features of copula functions as well as the copula families considered in this study. A more rigorous and detailed introduction to copula modeling can be found in Cherubini et al. (2004), Joe (1997) and Nelsen (2006). For the bivariate case of two continuous random variables $X$ and $Y$ with marginal distributions $F_{X}$ and $F_{Y}$, respectively, and joint distribution function $F_{X Y}(x, y)$, Sklar's theorem can be formulated as follows:

$$
F_{X Y}(x, y)=C\left(F_{X}(x), F_{Y}(y)\right)
$$

where $C$ denotes the copula function that describes the whole dependence structure between $X$ and $Y$. If the marginal distributions are continuous, then $C$ is uniquely determined on $\operatorname{Ran} F_{X} \times \operatorname{Ran} F_{Y}$. Conversely, if $C$ is a copula, then the function $F_{X Y}$ in Eq. (1) is a joint distribution function with margins $F_{X}$ and $F_{Y}$.

An important property of copulas is that they can be used to characterize the dependence between two random variables in the tails of their joint distribution, commonly referred to as tail dependence. Intuitively, the tail dependence reflects the propensity of two variables to experience extreme upward or downward comovements. It is very helpful for measuring the tendency of financial markets to crash or boom together. Such dependence is usually evaluated through upper- and lower-tail dependence coefficients denoted by $\lambda_{U}$ and $\lambda_{L}$, respectively, and defined as:

$$
\begin{aligned}
& \lambda_{U}=\lim _{u \rightarrow 1} \operatorname{Pr}\left[X \geq F_{X}^{-1}(u) \mid Y \geq F_{Y}^{-1}(u)\right]=\lim _{u \rightarrow 1} \frac{1-2 u+C(u, u)}{1-u} \\
& \lambda_{L}=\lim _{u \rightarrow 0} \operatorname{Pr}\left[X \leq F_{X}^{-1}(u) \mid Y \leq F_{Y}^{-1}(u)\right]=\lim _{u \rightarrow 0} \frac{C(u, u)}{u}
\end{aligned}
$$

where $F_{X}^{-1}(u)$ and $F_{Y}^{-1}(u)$ are the marginal quantile functions and $\lambda_{U}, \lambda_{L} \in[0,1]$. Two variables exhibit lower (upper) tail dependence if $\lambda_{L}>0 \cdot\left(\lambda_{U}>0\right)$. Larger values of $\lambda_{U}\left(\lambda_{L}\right)$ indicate greater tendency of the data to cluster in the upper (lower) tail of the joint distribution, in which case the variables are said to be upper (lower) tail dependent. The case of $\lambda_{U}=\lambda_{L}=0$ corresponds to the absence of dependence in the tails.

Among the wide range of copula functions available, four well-known copulas, namely the Gaussian, Student- $t$, rotated Gumbed and Symmetrized Joe-Clayton (SJC) copulas, are employed in this paper. Next, this appendix provides the general forms of these copula functions.

The bivariate Gaussian or Normal copula $(\mathrm{N})$ is defined as:

$$
C_{N}(u, v ; \rho)=\Phi_{\rho}\left(\Phi^{-1}(u), \Phi^{-1}(v)\right)
$$

where $\Phi_{\rho}$ is the standard bivariate normal cumulative distribution function with linear correlation $\rho$ and $\Phi^{-1}$ denotes the inverse of the standard univariate normal cumulative distribution function. The Gaussian copula is symmetric and has zero tail dependence. 
Table A1

Summary of related literature using copula models.

\begin{tabular}{|c|c|c|c|c|c|}
\hline Authors & Period & Data & Sample & Copula functions & Findings \\
\hline $\begin{array}{l}\text { Chang and Hsueh } \\
\text { (2013) }\end{array}$ & 2005-2011 & $\begin{array}{l}\text { Daily stock and long-term } \\
\text { government bond returns }\end{array}$ & Asia-Pacific countries & $\begin{array}{l}\text { Constant and time-varying } \\
\text { copulas (Gaussian, rotated } \\
\text { Clayton, rotated Gumbel and } \\
\text { rotated Joe-Clayton) }\end{array}$ & $\begin{array}{l}\text { Evidence of Flight-to-Quality } \\
\text { effects, which are intensified } \\
\text { during the financial crisis } \\
\text { period }\end{array}$ \\
\hline $\begin{array}{l}\text { Chui and Yang } \\
\text { (2012) }\end{array}$ & $\begin{array}{l}1983-2008 \\
(1998-2008 \text { for } \\
\text { Germany) }\end{array}$ & $\begin{array}{l}\text { Daily returns of stock index } \\
\text { futures and government bond } \\
\text { futures }\end{array}$ & $\begin{array}{l}\text { United States, UK and } \\
\text { Germany }\end{array}$ & $\begin{array}{l}\text { Static and conditional copulas } \\
\text { (Gaussian and Symmetrized } \\
\text { Joe-Clayton) }\end{array}$ & $\begin{array}{l}\text { Stock and bond markets more } \\
\text { interdependent during bad } \\
\text { times for the US and the UK. } \\
\text { Flight-to-Quality effects in } \\
\text { Germany }\end{array}$ \\
\hline $\begin{array}{l}\text { Durand et al. } \\
\text { (2010) }\end{array}$ & $1952-2003$ & $\begin{array}{l}\text { Quarterly returns on stock and } \\
30 \text {-year bond price indices }\end{array}$ & United States & $\begin{array}{l}\text { Flight-to-Quality copula } \\
\text { (combination of the Frank } \\
\text { copula and the Gumbel copula) }\end{array}$ & $\begin{array}{l}\text { In general, positive } \\
\text { relationship between stock and } \\
\text { long-term bond returns. } \\
\text { Flight-to-Quality effects in } \\
\text { extreme market conditions }\end{array}$ \\
\hline $\begin{array}{l}\text { Gonzalo and Olmo } \\
\text { (2005) }\end{array}$ & 1997-2004 & $\begin{array}{l}\text { Daily returns of Dow Jones } \\
\text { stock index and } 2 \text {-year and } \\
30 \text {-year corporate bond indices }\end{array}$ & United States & $\begin{array}{l}\text { A new copula derived from the } \\
\text { multivariate extreme value } \\
\text { theory }\end{array}$ & $\begin{array}{l}\text { Flight-to-Quality effects } \\
\text { between stock and } 2 \text {-year bond } \\
\text { returns, while stock and } \\
30 \text {-year bond returns are } \\
\text { almost independent }\end{array}$ \\
\hline $\begin{array}{l}\text { Nguyen and } \\
\text { Nguyen (2014) }\end{array}$ & $1992-2008$ & $\begin{array}{l}\text { Daily returns of stock price } \\
\text { index futures, long-term } \\
\text { government bond futures and } \\
\text { 3-month Treasury bill futures }\end{array}$ & $\begin{array}{l}\text { Australia and United } \\
\text { States }\end{array}$ & $\begin{array}{l}\text { Bivariate static and conditional } \\
\text { copulas (Gaussian and } \\
\text { Symmetrized Joe-Clayton) }\end{array}$ & $\begin{array}{l}\text { Time-varying dependence } \\
\text { between stock-bond and } \\
\text { stock-money markets. } \\
\text { Flight-to-Quality effects from } \\
\text { the beginning of the global } \\
\text { financial crisis }\end{array}$ \\
\hline $\begin{array}{l}\text { Wu and Liang } \\
\text { (2011) }\end{array}$ & 1992-2009 & $\begin{array}{l}\text { Weekly returns of S\&P } 500 \\
\text { futures and } 10 \text {-year Treasury } \\
\text { bond futures }\end{array}$ & United States & $\begin{array}{l}\text { Dynamic copulas (Gaussian, } \\
\text { Student-t, Clayton, survival } \\
\text { Clayton and mixture Clayton) }\end{array}$ & Evidence of Flight-to-Quality \\
\hline Wu and Lin (2014) & 1992-2009 & $\begin{array}{l}\text { Weekly returns of S\&P } 500 \\
\text { futures and } 10 \text {-year Treasury } \\
\text { bond futures }\end{array}$ & United States & $\begin{array}{l}\text { Constant and dynamic copulas } \\
\text { (Gaussian, Student-t, Clayton, } \\
\text { survival Clayton and mixture } \\
\text { Clayton) }\end{array}$ & $\begin{array}{l}\text { Stock-bond comovement } \\
\text { especially significant during } \\
\text { periods of market turbulence }\end{array}$ \\
\hline
\end{tabular}


The bivariate Student- $t$ copula takes the following form:

$$
C_{S T}(u, v ; \rho, v)=T\left(t_{v}^{-1}(u), t_{v}^{-1}(v)\right)
$$

where $T$ is the bivariate Student- $t$ cumulative distribution function with degree of freedom $v$ and correlation coefficient $\rho$, and $t_{v}^{-1}$ denotes the inverse of the standard univariate Student- $t$ distribution function. This copula allows for symmetric dependence in the tails, which is given by $\lambda_{U}=\lambda_{L}=2 t_{v+1}(-\sqrt{v+1} \sqrt{1-\rho} / \sqrt{1+\rho})>0$.

The rotated Gumbel copula allows for lower tail dependence, while upper tail dependence is zero. This copula is given by:

$$
C_{R G}(u, v ; \delta)=u+v-1+C_{G}(1-u, 1-v ; \delta)
$$

where $\delta_{t}$ is the dependence parameter.

The SJC copula was developed by Patton (2006) as a modification of the original Joe-Clayton (JC) copula. The SJC copula allows for both upper and lower tail dependence and includes symmetric dependence as a special case. This copula can be written as:

$$
C_{S J C}\left(u, v ; \lambda_{U}, \lambda_{L}\right)=0.5\left(C_{J C}\left(u, v ; \lambda_{U}, \lambda_{L}\right)+C_{J C}\left(1-u, 1-v ; \lambda_{U}, \lambda_{L}\right)+u+v-1\right)
$$

where $C_{J C}\left(u, v ; \lambda_{U}, \lambda_{L}\right)$ denotes the Joe-Clayton copula defined as:

$$
C_{J C}\left(u, v ; \lambda_{U}, \lambda_{L}\right)=1-\left(1-\left\{\left[1-(1-u)^{\kappa}\right]^{-\gamma}+\left[1-(1-v)^{\kappa}\right]^{-\gamma}-1\right\}^{-1 / \gamma}\right)^{1 / \kappa}
$$

where $\kappa=1 / \log _{2}\left(2-\lambda_{U}\right), \gamma=-1 / \log _{2}\left(\lambda_{L}\right), \lambda_{L} \in(0,1)$ and $\lambda_{U} \in(0,1)$

Patton (2006) introduced the dynamic or conditional copulas to take into account the time variation in the dependence structure. Following Patton (2006), the dynamics of the time-varying dependence between stock and government bond returns in the conditional Gaussian and Student- $t$ copulas is specified as:

$$
\rho_{t}=\Lambda\left(\psi_{0}+\psi_{1} \rho_{t-1}+\psi_{2} \frac{1}{q} \sum_{j=1}^{q} \Phi^{-1}\left(u_{t-j}\right) \cdot \Phi^{-1}\left(v_{t-j}\right)\right)
$$

where $\Lambda(x)=\left(1-e^{-x}\right)\left(1+e^{-x}\right)^{-1}$ is the modified logistic transformation designed to hold the value of $\rho_{t}$ within the $(-1,1)$ interval at all times. This equation assumes that the copula dependence parameter follows an ARMA(1,q)-type process in which $\Psi_{0}$ is a constant, the autoregressive term, $\Psi_{1} \rho_{t-1}$, captures the persistence effect and the last term, represented by the average of the product of the last $q$ observations of the transformed variables, reflects the variability of the dependence. For the Student- $t$ copula, the same specification is used with $\Phi^{-1}(\cdot)$ being replaced by $t_{v}^{-1}(\cdot)$.

Similarly, the dynamics of the conditional rotated Gumbel copula is described by:

$$
\delta_{t}=\omega+\beta \delta_{t-1}+\alpha \frac{1}{q} \sum_{j=1}^{q}\left|u_{t-j}-v_{t-j}\right|
$$

For the conditional SJC copula, the evolution equations for the tail dependence parameters are (Patton, 2006):

$$
\begin{aligned}
& \lambda_{t}^{U}=\Delta\left(\omega_{U}+\beta_{U} \lambda_{t-1}^{U}+\alpha_{U} \frac{1}{q} \sum_{j=1}^{q}\left|u_{t-j}-v_{t-j}\right|\right) \\
& \lambda_{t}^{L}=\Delta\left(\omega_{L}+\beta_{L} \lambda_{t-1}^{L}+\alpha_{U} \frac{1}{q} \sum_{j=1}^{q}\left|u_{t-j}-v_{t-j}\right|\right)
\end{aligned}
$$

where $\Delta(x)=\left(1+e^{-x}\right)^{-1}$ is the logistic transformation used to keep $\lambda_{t}^{U}$ and $\lambda_{t}^{L}$ within the interval $(0,1)$ at all times. These equations show that the upper and lower tail dependence parameters follow 
an ARMA(1,q)-type process with an autoregressive term, $\beta_{U} \lambda_{t-1}^{U}$ and $\beta_{L} \lambda_{t-1}^{L}$, designed to capture persistence in dependence, and a forcing variable, which is the mean absolute difference between $u_{t}$ and $v_{t}$ over the last $q$ observations and captures the variation effect in dependence.

\section{Appendix C. The DCC-GARCH(1,1) model}

Let $r_{s, t}$ and $r_{b, t}$ be stock and government bond returns for a given country at period $t$, the bivariate DCC-GARCH $(1,1)$ proposed by Engle (2002) can be formulated in this context as follows:

$$
\left(\begin{array}{c}
r_{s, t} \\
r_{b, t}
\end{array}\right)=\left(\begin{array}{c}
c_{s} \\
c_{b}
\end{array}\right)+\left(\begin{array}{c}
\varepsilon_{s, t} \\
\varepsilon_{b, t}
\end{array}\right), \quad\left(\begin{array}{c}
\varepsilon_{s, t} \\
\varepsilon_{b, t}
\end{array}\right) \mid \Omega_{t-1} \approx N\left(0, H_{t}\right)
$$

where $c_{s}$ and $c_{b}$ denote the conditional expectation of stock and bond returns, respectively, given the information set available at time $t-1, \Omega_{t-1}, \varepsilon_{s, t}$ and $\varepsilon_{b, t}$ represent the error terms of stock and bond return equations, respectively, and $H_{t}$ is the conditional variance-covariance matrix. In this framework, the matrix $H_{t}$ can be expressed as:

$$
H_{t}=\left(\begin{array}{cc}
h_{s, t}^{2} & h_{s b, t} \\
h_{s b, t} & h_{b, t}^{2}
\end{array}\right)=\left(\begin{array}{cc}
h_{s, t} & 0 \\
0 & h_{b, t}
\end{array}\right)\left(\begin{array}{cc}
1 & \rho_{t} \\
\rho_{t} & 1
\end{array}\right)\left(\begin{array}{cc}
h_{s, t} & 0 \\
0 & h_{b, t}
\end{array}\right)=D_{t} R_{t} D_{t}
$$

where $h_{s, t}^{2}$ and $h_{b, t}^{2}$ are the conditional variance of stock and government bond returns at time $t$, respectively, $h_{s b, t}$ denotes the conditional covariance between stock and bond returns at time $t$ and $\rho_{t}$ represents the linear correlation coefficient. $D_{t}$ is a diagonal matrix of conditional standard deviations for return series, obtained from modeling the respective conditional variances through a univariate GARCH( 1,1$)$ process. In turn, $R_{t}$ denotes the conditional correlation matrix and is defined as:

$$
R_{t}=\left[\operatorname{diag}\left(Q_{t}\right)^{-1 / 2}\right] Q_{t}\left[\operatorname{diag}\left(Q_{t}\right)^{-1 / 2}\right]
$$

where $Q_{t}$ is a symmetric positive definite matrix given by

$$
Q_{t}=\left(1-\theta_{1}-\theta_{2}\right) \bar{Q}+\theta_{1}\left(\eta_{t-1} \eta_{t-1}^{\prime}\right)+\theta_{2} Q_{t-1}
$$

where $\theta_{1}$ and $\theta_{2}$ represent non-negative scalars satisfying $\theta_{1}+\theta_{2}<1$ and $\bar{Q}$ is the unconditional (timeinvariant) covariance matrix of standardized residuals $\left(\eta_{i t}=\varepsilon_{i t} / \sqrt{h_{i t}}\right)$.

As is suggested by Engle (2002), the DCC-GARCH model can be estimated consistently in two steps by using maximum likelihood techniques.

\section{References}

Aloui, C., Hammoudeh, S., \& ben Hamida, H. (2015). Global factors driving structural changes in the co-movement between sharia stocks and sukuk in the Gulf Cooperation Council countries. North American Journal of Economics and Finance, 31, 311-329.

Andersson, M., Krylova, E., \& Vähämaa, S. (2008). Why does the correlation between stock and bond returns vary over time? Applied Financial Economics, 18, 139-151.

Baele, L., Bekaert, G., \& Inghelbrecht, K. (2010). The determinants of stock and bond return comovements. Review of Financial Studies, 23, 2374-2428.

Baur, D. G., \& Lucey, B. M. (2009). Flights and contagion - An empirical analysis of stock-bond correlations. Journal of Financial Stability, 5, 339-352.

Brière, M., Chapelle, A., \& Szafarz, A. (2012). No contagion, only globalization and flight to quality. Journal of International Money and Finance, 31, 1729-1744.

Campbell, J. Y., \& Ammer, J. (1993). What moves the stock and bond markets? A variance decomposition for long term asset returns. Journal of Finance, 48, 3-37.

Chang, C. L., \& Hsueh, P. L. (2013). An investigation of the flight-to-quality effect: Evidence from Asia-Pacific countries. Emerging Markets Finance and Trade, 49, 53-69.

Cherubini, U., Luciano, E., \& Vecchiato, W. (2004). Copula methods in finance. Chichester: Wiley Finance Series.

Chiang, T. C., Li, J., \& Yang, S. Y. (2014). Dynamic stock-bond return correlations and financial market uncertainty. Review of Quantitative Finance and Accounting, http://dx.doi.org/10.1007/s11156-013-0430-4

Chui, C. M., \& Yang, J. (2012). Extreme correlation of stock and bond futures markets: International evidence. The Financial Review, 47, 565-587.

Connolly, R., Sun, L., \& Stivers, C. T. (2005). Stock market uncertainty and the stock-bond return relation. Journal of Financial and Quantitative Analysis, 40, 161-194. 
Dacjman, S. (2012). Comovement between stock and bond markets and the flight-to-quality during financial market turmoil - A case of the Eurozone countries most affected by sovereign debt crisis of 2010-2011. Applied Economics Letters, 19, 1655-1662.

Durand, R. B., Junker, M., \& Szimayer, A. (2010). The flight-to-quality effect: A copula-based analysis. Accounting and Finance, $50,281-299$.

Engle, R. F. (2002). Dynamic conditional correlation: A simple class of multivariate generalized autoregressive conditional heteroskedasticity models. Journal of Business and Economic Statistics, 20, 339-350.

Evrim-Mandaci, P., Kahyaoglu, H., \& Cagli, E. C. (2011). Stock and bond market interactions with two regime shifts: Evidence from Turkey. Applied Financial Economics, 21, 1355-1368.

Genest, C., Ghoudi, K., \& Rivest, L. P. (1995). A semiparametric estimation procedure of dependence parameters in multivariate families of distributions. Biometrika, 82, 543-552.

Gómez-Puig, M., Sosvilla-Rivero, S., \& Ramos-Herrera, M. C. (2014). An update on EMU sovereign yield spread drivers in times of crisis: A panel data analysis. North American Journal of Economics and Finance, 30, 133-153.

Gonzalo, J., \& Olmo, J. (2005). Contagion versus flight-to-quality in financial markets. Working Paper 05-18, Economics Series 10. Universidad Carlos III Madrid.

Gulko, L. (2002). Decoupling: If the US treasury repays its debt, what then? Journal of Portfolio Management, 28, 59-66.

Heinen, A., \& Valdesogo, A. (2008). Asymmetric CAPM dependence for large dimensions: The canonical vine autoregressive model. CORE Discussion Paper 2009-069. Belgium: Université Catholique de Louvain.

Ilmanen, A. (2003). Stock-bond correlations. Journal of Fixed Income, 12, 55-66.

Joe, H. (1997). Multivariate models and dependence concepts. London: Chapman Hall.

Keim, D. B., \& Stambaugh, R. F. (1986). Predicting returns in the stock and bond markets. Journal of Financial Economics, 17, 357-390.

Kim, S., Moshirian, F., \& Wu, E. (2006). Evolution of international stock and bond market integration: Influence of the European Monetary Union. Journal of Banking and Finance, 30, 1507-1534.

Kim, G., Silvapulle, M., \& Silvapulle, P. (2007). Comparison of semiparametric and parametric methods for estimating copulas. Computational Statistics and Data Analysis, 51, 2836-2850.

Klein, J., Köck, C., \& Tinkl, F. (2010). Spatial-serial dependency in multivariate GARCH models and dynamic copulas: A simulation study. Ekonomia Menedżerska, 7, 43-62.

Lee, C. C., Huang, W. L., \& Lin, C. H. (2013). The dynamic interactions among the stock, bond and insurance markets. North American Journal of Economics and Finance, 26, 28-52.

Lee, T. H., \& Long, X. (2009). Copula-based multivariate GARCH model with uncorrelated dependent errors. Journal of Econometrics, 150, 207-218.

Li, L. (2002). Macroeconomic factors and the correlation of stock and bond returns. Yale International Center for Finance Working Paper No. 02-46.

Nelsen, R. (2006). An introduction to copulas (second ed.). New York: Springer.

Nguyen, C., \& Nguyen, T. (2014). Analyzing dependence structure of equity, bond and money markets by using time-varying copulas. International Journal of Economics and Finance, 6, 37-54.

Patton, A. J. (2006). Modelling asymmetric exchange rate dependence. International Economic Review, 47, 527-556.

Perego, E., \& Vermeulen, W. N. (2013). Macroeconomic determinants of European stock and government bond correlations: A tale of two regions. CREA discussion paper.

Reboredo, J. C., \& Ugando, M. (2014). US dollar exchange rate and food price dependence: Implications for portfolio risk management. North American Journal of Economics and Finance, 30, 72-89.

Reboredo, J. C., \& Ugolini, A. (2015). A vine-copula conditional value-at-risk approach to systemic sovereign debt risk for the financial sector. North American Journal of Economics and Finance, 32, 98-123.

Rodríguez, J. C. (2007). Measuring financial contagion: A Copula approach. Journal of Empirical Finance, 14, 401-423.

Shiller, R. J., \& Beltratti, A. (1992). Stock prices and bond yields: Can their comovements be explained in terms of present value models. Journal of Monetary Economics, 30, 25-46.

Scruggs, J. T., \& Glabadanidis, P. (2003). Risk premia and the dynamic covariance between stock and bond returns. Journal of Financial and Quantitative Analysis, 38, 295-316.

Sklar, A. (1959). Fonctions de repartition à $n$ dimensions et leurs marges. Publications de l'Institut de Statistique de L'Université de Paris, 8, 229-231.

Thanh, L. T., \& Barassi, M. (2014). Multivariate copula: An application to emerging financial markets. In Paper presented in the 2014 Vietnam Economists Annual Meeting (VEAM).

Wu, C. C., \& Liang, S. S. (2011). The economic value of range-based covariance between stock and bond returns with dynamic copulas. Journal of Empirical Finance, 18, 711-727.

Wu, C. C., \& Lin, Z. Y. (2014). An economic evaluation of stock-bond return comovements with copula-based GARCH models. Quantitative Finance, 14, 1283-1296.

Yang, L., \& Shigeyuki, H. (2015). Interdependence between the bond markets of CEEC-3 and Germany: A wavelet coherence analysis. The North American Journal of Economics and Finance, 32, 124-138. 